\title{
Bilateral bipartite trapezoid: a rare anatomical variant
}

\author{
Christopher Sparks, ${ }^{1}$ Philipp Riede, ${ }^{1}$ James Teh, ${ }^{1}$ Kirsten van Langevelde ${ }^{1,2}$
}

Radiology, Oxford University Hospitals NHS Foundation Trust Nuffield Orthopaedic Centre, Oxford, UK

${ }^{2}$ Radiology, Leids Universitair Medisch Centrum, Leiden, The Netherlands

\section{Correspondence to}

Dr Kirsten van Langevelde; kirstenvanlangevelde@gmail. com

Accepted 14 January 2020

\section{DESCRIPTION}

A 54-year-old man presented to the emergency department following a fall onto his outstretched right hand. Initial radiographs were considered negative for a fracture. A subsequently performed MRI of the wrist to exclude a radiographically occult scaphoid fracture demonstrated a linear high signal cleft across the trapezoid bone, but no discrete fracture line. CT confirmed the presence of a cleft through the waist of the trapezoid with well corticated margins (figure 1). In retrospect, the initial radiographs showed the split trapezoid on the lateral view. There was no change in appearances compared with radiographs obtained 10 years previously.

Radiographs and a CT performed due to a fall onto the outstretched contralateral (left) hand 11 and 2 years previously revealed similar appearances of the left wrist with a split left trapezoid (figure 2). Based on the longevity of these changes, the symmetrical bone morphology and the rarity of an isolated trapezoid fracture, a diagnosis of bilateral bipartite trapezoids was made.

The trapezoid is an irregular, boot-shaped bone, lying in the distal carpal row. ${ }^{1}$ Encircled by carpal bones and the base of the second metacarpal, and with strong intercarpal ligaments binding it in place, the trapezoid is the least commonly fractured carpal bone in isolation, with few published cases in the literature. ${ }^{2-4}$

Carpal bone bipartition is an anatomical variant that occurs due to the formation of two cartilaginous centres rather than one, or non-union of two ossification centres. ${ }^{5}$ The most common bipartite carpal is the scaphoid. ${ }^{5}$ To date, there exists a single case report describing unilateral right bipartite trapezoid in a 17-year-old man identified on radiographs and CT following fall onto the outstretched hand. ${ }^{6}$ No imaging of the contralateral wrist was undertaken to confirm the presence of bilateral bipartite trapezoids.

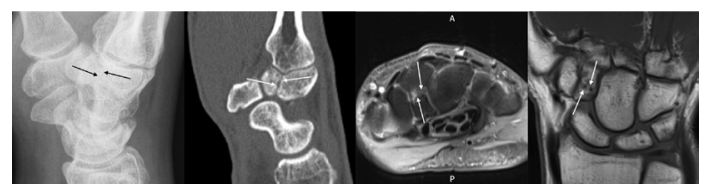

C) BMJ Publishing Group Limited 2020. No commercial re-use. See rights and permissions. Published by BMJ.

To cite: Sparks C, Riede P, Teh J, et al. BMJ Case Rep 2020;13:e233911. doi:10.1136/bcr-2019233911
Figure 1 Right wrist (all imaging from 2019). From left to right: lateral radiograph showing the bipartite trapezoid (black arrows); sagittal CT confirmed the cleft with sclerotic margins (white arrows); axial proton density fat saturated MRI showed oedema within the fibrocartilaginous cleft (white arrows); coronal proton density fat saturated MRI showed small cystic change in the trapezoid (white arrows).

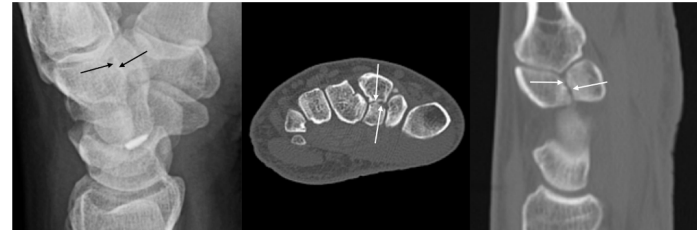

Figure 2 Left wrist (all imaging from 2008). From left to right: lateral radiograph showing the bipartite trapezoid (black arrows); axial CT reformat confirmed the cleft and showed adjacent small cystic change (white arrows); sagittal CT confirmed the cleft with sclerotic margins (white arrows).

Two cases of bilateral bipartite trapezoids have been published, with this representing the first described case of a living patient with bilateral bipartite trapezoids. ${ }^{5}$ Anatomical anthropology studies assessing skeletal specimens describe a larger, flatter, oval shaped dorsal segment, with a smaller cubical palmar segment, which is reflected in our cases appearance. ${ }^{5}$ Second, roughening between the two surfaces of the dorsal and palmar trapezoid portions was described, indicating a fibrous or fibrocartilaginous connection, confirmed in our case.

The primary differential diagnosis for a bipartite trapezoid is an isolated acute fracture or non-union of a previous fracture. Associated fractures point the clinician towards a trapezoid fracture. The proposed mechanism of isolated trapezoid fracture is via the transfer of energy through the index finger metacarpal shaft, either axially or through bending force. Direct trauma to the base of the metacarpal or the dorsum of the hand has also been described, although these often have concurrent injuries to the index finger metacarpal base. ${ }^{4}$

The overlapping appearances of the carpal and metacarpal bones make accurate diagnosis of trapezoid fracture or bipartition difficult on plain radiographs, therefore, cross-sectional imaging with CT or MRI is required. ${ }^{4}$ Minimally displaced fractures

\section{Learning points}

- A bipartite trapezoid is a rare anatomical variant that may mimic trapezoid fracture.

- Cross-sectional imaging with CT for bony anatomy and/or MRI to assess for bone marrow oedema are recommended to differentiate between trapezoid bipartition and fracture.

- If there is suspicion of a bipartite trapezoid, imaging of the contralateral wrist to assess for bilateral bipartition may aid diagnosis in equivocal cases. 
are treated conservatively. For displaced fractures or those with associated metacarpal or carpal fractures operative fixation is required. ${ }^{4}$

Correction notice This article has been corrected since it was first published online. The figures are now swapped correctly to match the captions.

Contributors CS drafted the manuscript and prepared the images. PR reviewed the images and drafted the manuscript. JT reviewed the images and the manuscript. KvL selected the case and drafted and reviewed the manuscript.

Funding The authors have not declared a specific grant for this research from any funding agency in the public, commercial or not-for-profit sectors.

Competing interests None declared.

Patient consent for publication Obtained.
Provenance and peer review Not commissioned; externally peer reviewed.

\section{REFERENCES}

1 Matshes EW, Burbridge B, Sher B, et al. Human Osteology and skeletal radiology: an atlas and guide. Boca Raton, FL: CRC Press, 2004: 302-3.

2 Sadowski RM, Montilla RD. Rare isolated trapezoid fracture: a case report. Hand 2008;3:372-4.

3 Afifi N, Lu JJ. A rare isolated trapezoid fracture. West J Emerg Med 2011;12:523-4.

4 Gruson KI, Kaplan KM, Paksima N. Isolated trapezoid fractures: a case report with compilation of the literature. Bull NYU Hosp Jt Dis 2008;66:57-60.

5 Burnett SE, Stojanowski CM, Mahakkanukrauh P. Six new examples of the bipartite trapezoid bone: morphology, significant population variation, and an examination of pre-existing criteria to identify bipartition of individual carpal bones. Ann Anat 2015;198:58-65.

6 Barai A. Bipartite trapezoid: a rare entity. Eurorad case 5887, 2007. Available: https:// www.eurorad.org/case/5887 [Accessed 18 Nov 2019].

Copyright 2020 BMJ Publishing Group. All rights reserved. For permission to reuse any of this content visit

https://www.bmj.com/company/products-services/rights-and-licensing/permissions/

BMJ Case Report Fellows may re-use this article for personal use and teaching without any further permission.

Become a Fellow of BMJ Case Reports today and you can:

Submit as many cases as you like

Enjoy fast sympathetic peer review and rapid publication of accepted articles

- Access all the published articles

Re-use any of the published material for personal use and teaching without further permission

\section{Customer Service}

If you have any further queries about your subscription, please contact our customer services team on +44 (0) 2071111105 or via email at support@bmj.com.

Visit casereports.bmj.com for more articles like this and to become a Fellow 